\title{
Human postnatal dental pulp cells co-differentiate into osteoblasts and endotheliocytes: a pivotal synergy leading to adult bone tissue formation
}

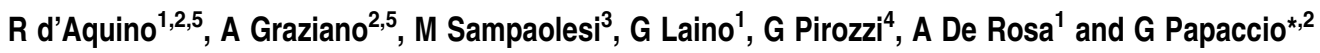

Stromal stem cells from human dental pulp (SBP-DPSCs) were used to study osteogenic differentiation in vitro and in vivo. We previously reported that SBP-DPSCs are multipotent stem cells able to differentiate into osteoblasts, which synthesize threedimensional woven bone tissue chips in vitro. In this study, we followed the temporal expression pattern of specific markers in SBP-DPSCs and found that, when differentiating into osteoblasts, they express, besides osteocalcin, also flk-1 (VEGF-R2). In addition, $30 \%$ of them expressed specific antigens for endothelial cells, including CD54, von-Willebrand (domain 1 and 2), CD31 (PECAM-1) and angiotensin-converting enzyme. Interestingly, we found endotheliocytes forming vessel walls, observing that stem cells synergically differentiate into osteoblasts and endotheliocytes, and that flk-1 exerts a pivotal role in coupling osteoblast and endotheliocyte differentiation. When either SBP-DPSCs or bone chips obtained in vitro were transplanted into immunocompromised rats, they generated a tissue structure with an integral blood supply similar to that of human adult bone; in fact, a large number of $\mathrm{HLA}-1^{+}$vessels were observed either within the bone or surrounding it in a periosteal layer. This study provides direct evidence to suggest that osteogenesis and angiogenesis mediated by human SBP-DPSCs may be regulated by distinct mechanisms, leading to the organization of adult bone tissue after stem cell transplantion.

Cell Death and Differentiation (2007) 14, 1162-1171. doi:10.1038/sj.cdd.4402121; published online 9 March 2007

Stem cells are the natural and direct source from which stable differentiated cells are generated, leading to tissue formation. It has been suggested that the human body contains several 'Ioci' or 'niches', inhabited by a significant number of stem cells. $^{1,2}$ Among these, dental pulp, entrapped within the 'sealed niche' of the pulp chamber, is an extremely rich site for stem cell collection. These stem cells are called DPSCs (dental pulp stem cells), ${ }^{3}$ when found in adults, and SHEDs (stem cells from human exfoliated deciduous), ${ }^{4}$ when found in deciduous teeth.

Recently, we showed that some of these stromal DPSCs (SBP-DPSCs) $^{5}$ and stromal SHEDs (SBP-SHEDs) ${ }^{6}$ differentiate into various cells and tissues under particular conditions. Cytotypes include neural progenitors, adipocytes, myotubes and pre-osteoblasts; the latter are then able to produce three-dimensional bone tissue chips in vitro that, after in vivo transplantation in immunosuppressed rats, are quickly remodelled into a lamellar bone.

In vitro bone regeneration studies are limited by the main difficulty of obtaining a cytotype capable of forming a complete tissue and not only a monolayer or cells surrounded by a mineralized matrix. Owing to their high proliferation rate and efficiency in producing bone chips, DPSCs ${ }^{5,6}$ seem to be better candidates for the study of bone formation than bone marrow stem cells (BMSCs), ${ }^{7}$ whose efficiency is limited by the fact that they differentiate into osteoblasts and produce small calcified nodules and not chips of bone tissue. Moreover, complete differentiation with subsequent tissue formation, including an adequate blood supply, is of paramount importance for tissue repair and transplantation. With this aim, the use of appropriate scaffolds allows to address the issues of tissue shape and dimensions. The importance of these scaffolds is shown by the fact that human tissue development is driven by surface adhesions and cellular contacts. ${ }^{8-12}$

Therefore, we decided to perform this research with the aim to obtain a complete bone tissue formation. For this reason we studied the differentiation process leading to in vitro woven bone formation in order to better understand the mechanisms involved as well as bone tissue formation after transplantation in vivo. Here, we show that SBP-DPSCs alter their antigenic pattern during differentiation. Interestingly, we found that within the population expressing flk-1, about $30 \%$ of cells expressed vasculogenic markers, demonstrating that synergic differentiation into osteoblasts and endotheliocytes takes place.

In fact, we show, for the first time, that vessels are detectable within the woven bone chips produced in vitro. Moreover, we demonstrate that after in vivo transplantation,

\footnotetext{
${ }^{1}$ Dipartimento di Discipline Odontostomatologiche, Ortodontiche e Chirurgiche, Università Secondo Ateneo di Napoli, Napoli, Italy; ${ }^{2}$ Dipartimento di Medicina Sperimentale, Sezione di Istologia ed Embriologia, Università Secondo Ateneo di Napoli, Napoli, Italy; ${ }^{3}$ DIBIT Dipartimentale San Raffaele Scientific Institute, Università Vita e Salute, Stem Cell Research Institute, Milan, Italy and ${ }^{4}$ UOS Dipartimentale, Diagnostica Molecolare, Analisi d'immagine e citometría a flusso, Istituto Nazionale Tumori 'G. Pascale', Napoli, Italy

${ }^{*}$ Corresponding author: G Papaccio, Department of Experimental Medicine, Section of Histology and Embryology, Second University of Naples, 5 via L Armanni, 80138 Naples, Italy. Tel: + 39081 5666014; Fax: + 39081 5666015; E-mail: gianpaolo.papaccio@ unina2.it

${ }^{5}$ These authors equally contributed to the study

Keywords: postnatal stem cells; differentiation; endotheliocytes; osteogenesis; vasculogenesis

Abbreviations: BMSCs, bone marrow stem cells; SHEDs, stem cells from human exfoliated deciduous

Received 30.11.06; revised 01.2.07; accepted 02.2.07; Edited by RA Knight; published online 09.3.07
} 
there is a complete integration of vessels within the bone chips, and this leads to the formation of a vascularized bone tissue. These findings have been obtained for the first time both in vitro and in vivo, and are of great interest because they highlight that: (i) osteogenesis and vasculogenesis are interdependent in this model, recapitulating embryonic development in vivo; and (ii) this process is essential to obtain an adult tissue bone, ready for transplantation and surgical/clinical application in tissue repair.

\section{Results}

Antigenic expression during differentiation. Single-cell suspensions of digested dental pulp cells were grown in lowdensity liquid culture. Significant cell proliferation started by day 6 and continued from this day onward.

Dental pulp cells were analyzed using flow cytometry and cell sorting with the following antibodies: anti-CD117 (a membrane tyrosine-kinase interacting with the stem cell factor, SCF), anti-flk-1 (vascular endothelial growth factor receptor 2 - VEGFr-2) and anti-CD34 (markers of stromal stem cells), anti-CD45 (cell marker of hematopoietic origin) and anti-STRO-1.

At day 15 , cytofluorimetry showed that a significant number of cells were CD $117^{+} / \mathrm{CD} 34^{+} / \mathrm{flk}^{-1}{ }^{+}$, but $\mathrm{CD} 45^{-} / \mathrm{STRO}-1^{-}$ (Figure 1a). This was confirmed by semiquantitative RT-PCR analysis (Figure 1b, c). Almost all cells positive for the abovementioned antigens belonged to the 'side population', characterized by low forward and high side scatters.

Cell cycle analysis performed at day 22 , showed that total S-phase cells were about $20 \%$ and that all cells were euploid (Figure 1d). At this time point, CD $117^{+} / \mathrm{CD} 34^{+} / \mathrm{flk}-1^{+}$cells were more numerous than at day 15. Moreover, this population was now STRO-1 ${ }^{+}$. The persistence of negativity for CD45 clearly demonstrated that these cells were not derived from a hematopoietic source, although they were $\mathrm{CD} 4^{+}$, but it is well known that CD34 ${ }^{+} / \mathrm{CD} 45^{-}$cells, are of mesenchymal origin. The number of stem cells was sufficient for multiparametric sorting, using morphological criteria (i.e., identification of the side population by forward and side scatter) and antigenic criteria (i.e., positivity for CD117, CD34, flk-1 and STRO-1). After sorting, the obtained cell population was analyzed also with anti-CD90 and anti-CD133 antibodies (recognizing neuro-endothelial progenitor cells). The population was found to be $\mathrm{CD}^{+} / \mathrm{CD}^{+} 33^{+}$(Figure 1e). This evidences that the population is still undifferentiated, as well as potentially multipotent.

Sorted cells were cultured and negative cells were collected as controls.

To assess the proliferation and clonogenic potential of sorted cells, we performed a limiting dilution assay. After 3 weeks of culture, $92 \%$ of wells (442 out of 480 ), which were initially plated with three or four cells, contained colonies (formed of $>50$ cells) with a doubling time of $\approx 4$ days. Using only one cell per well, it was extremely difficult to obtain colonies.

At day 30, CD117 positivity disappeared, whereas cells were still STRO $-1^{+} / \mathrm{CD} 34^{+} / \mathrm{flk}-1^{+} / \mathrm{CD} 90^{+} / \mathrm{CD} 133^{+}$. At day 36, positivity for CD34 disappeared, whereas STRO-1 positivity was still present. This positivity disappeared only from day 40 onwards. The kinetics of CD117, CD34 and flk-1 was confirmed by semiquantitative RT-PCR analysis (Figure $1 b, c)$.

Cell cycle analysis performed from day 27 up to day 32 , showed that total S-phase cells ranged between 22 and $26 \%$ and that all cells were euploid.

Synergic differentiation of pre-osteoblasts into osteoblasts and endotheliocytes. As described above, after sorting, cells started to differentiate by day 30 and lost their stem cell markers (CD117, CD34, CD90 and CD133), expressing differentiation markers such as CD44 (Figure 2a). At day 40 , cells started to differentiate into two cytotypes from a common $\mathrm{flk}-1^{+} / \mathrm{STRO}-1^{+} / \mathrm{CD} 90^{+} / \mathrm{CD} 133^{+} / \mathrm{CD} 44^{+}$ progenitor: approximately $70 \%$ became $\mathrm{flk}-1^{+} / \mathrm{STRO}-1^{-} /$ $\mathrm{CD}_{4}{ }^{+} / \mathrm{RUNX}-2^{+}$and were considered osteogenic progenitor cells; the remaining $30 \%$, became flk- ${ }^{+} / \mathrm{STRO}-$ $1^{+} / \mathrm{CD} 44^{+} / \mathrm{CD} 54^{+}$and thus were considered endothelial progenitor cells. Among the latter cell population, we found a marked positivity also for von-Willebrand domains 1 and 2 and for angiotensin-converting enzyme (ACE) (Figure 2b). Osteocalcin positive $\left(\mathrm{OC}^{+}\right)$and $\mathrm{CD} 54^{+}$cells were detected within the flk-1 ${ }^{+} / \mathrm{STRO}-1^{-} / \mathrm{CD} 44^{+} / \mathrm{RUNX}-2^{+}$population at day 45 of culture. This demonstrates stem cell differentiation into osteoblasts. (Figure 2c).

At day 37, cell cycle analysis performed on the differentiated osteoblast population showed that cells in S phase were about $39 \%$ and that all cells were still euploid (Figure $2 d$ ).

To assess the multipotency of these stem cells, we performed differentiation protocols and obtained smooth muscle, adipocytes and neurons (Figure 3).

The antigen kinetics from day 15 onwards is shown in detail in Figure 4.

Histochemical, immunofluorescence and ultrastructural analyses. ALP positivity increased when cells differentiated, as described previously. ${ }^{6,7}$. Moreover, ALP was qualitatively different in undifferentiated and differentiated cells; 'nonspecific' ALP was expressed by all undifferentiated cells (Figure 5a); 'specific' ALP (bone-specific alkaline phosphatase (BAP)) was only detected within the ossification centres (Figure 5b), which also were positive for calcein. Positivity for BAP was assessed by immunofluorescence (Figure $5 \mathrm{c}$ ). Calcein staining (Figure $5 d$ ) confirms that these cells are osteoblasts involved in the ossification process.

Semiquantitative RT-PCR analysis confirmed that differentiated osteoblasts were positive for $\mathrm{OC}$ and bone sialo protein (BSP) (Figure 5e, f). Positivity for OC, BAP and BSP strongly evidences that these cells are involved in producing an extracellular matrix for hard tissue formation. In addition, these cells were always negative for dentin sialo phospho protein (DSPP), as assessed by RT-PCR analysis, further demonstrating that they were osteoblasts forming bone and not odontoblasts forming dentin. As previously described by us, ${ }^{5}$ woven bone chips are visible within the flasks by day 50 .

At the ultrastructural level, cells examined at day 22 immediately after cell sorting, were mainly round or oval in shape and contained a spherical nucleus, characterized by 
a
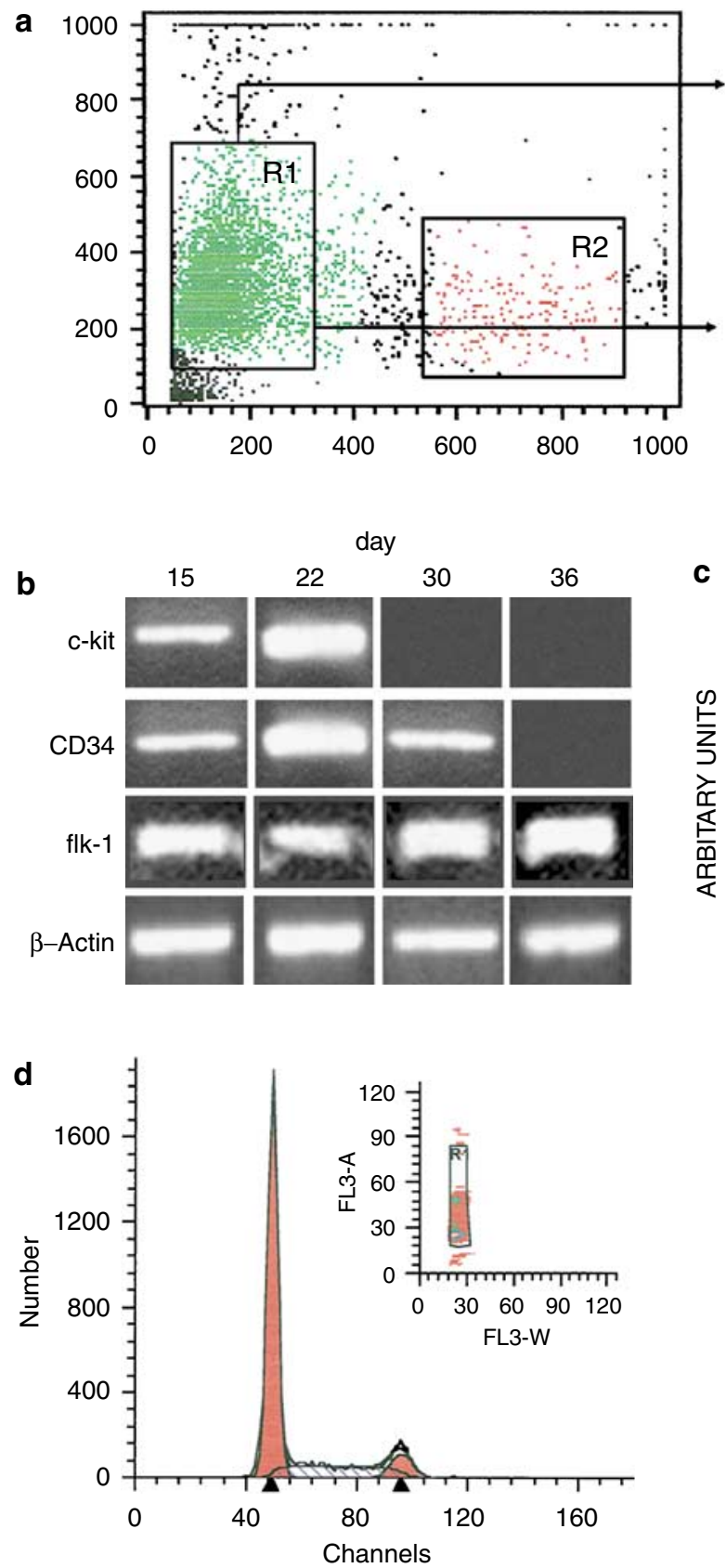

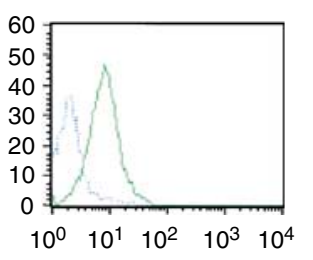
CD117-FITC

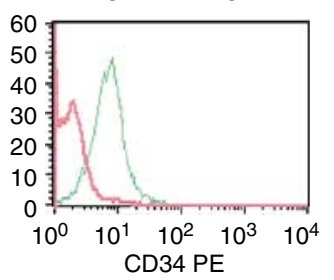

C

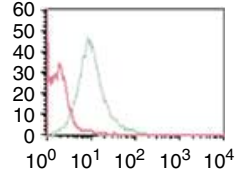

Flk-1 PE
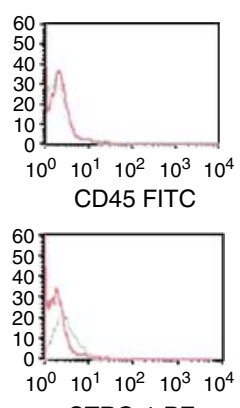

STRO-1 PE
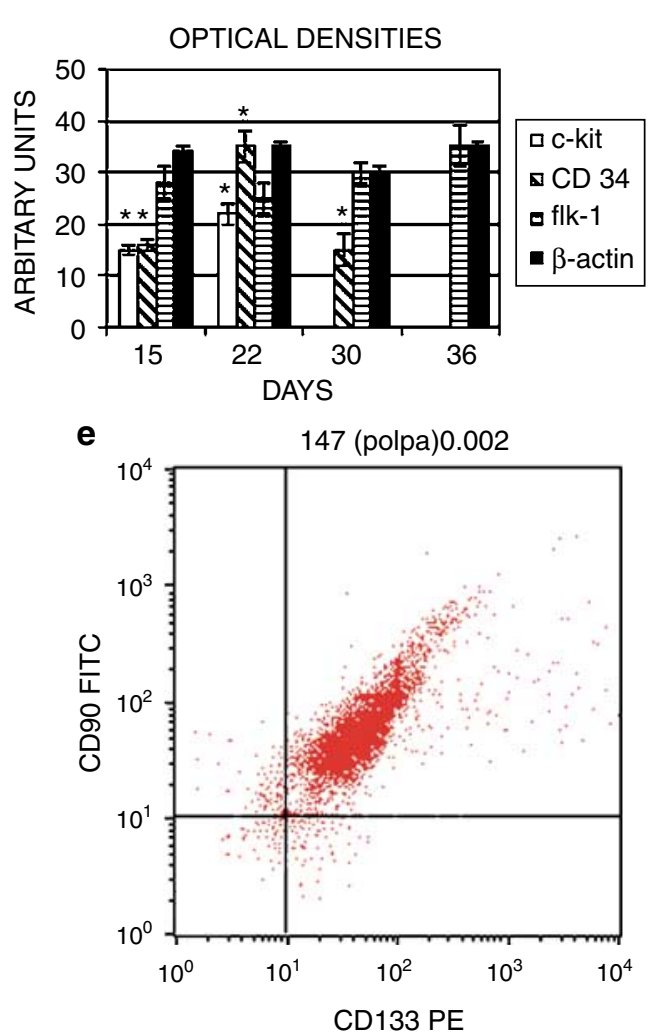

Figure 1 (a) Flow analysis at day 15, showing CD117 (c-kit) CD34 and flk-1 positivity, CD45 and STRO-1 negativity and the presence of two cell populations, called R1 and R2. (b) RT-PCR analyses of CD117 (c-kit), CD34 and flk-1, performed at days 15, 22, 30 and 36 of culture. (c) Semiquantitative analysis of RT-PCR. Optical quantification of band intensities was obtained with an Ultrascan Enhancer Laser Densitometer. OD are expressed in arbitrary units \pm S.D. of repeat numbers. (d) Cell cycle performed at day 15 of culture, evidencing that total S-phase cells were of about $20 \%$ and that all cells were euploid. (e) Flow analysis performed after sorting (day 22) shows CD90 and CD133 positivity. These markers identify neuro-endothelial progenitors

thin extensions (Figure 6a). Other morphological features included the formation of either one or two nucleoli, a rather extended cytoplasm containing small vesicles, as well as rudimental cysternae of endoplasmic reticulum. Scattered lysosome-like organelles and small, elongated mitochondria were contained within the cytoplasm. At days 40 and 60 , the presence of two different cytotypes were observed within the bone chips. Some cells had a cuboidal shape with a basal nucleus, an evident nucleolus and polarity of cytoplasmic organelles, an extremely extended rough endoplasmic reticulum with enlarged cysternae, numerous coated vesicles, a rather large Golgi apparatus and a ruffled membrane border (Figure 6b). These cells often formed a single layer (Figure 6c). All the reported ultrastructural observations 

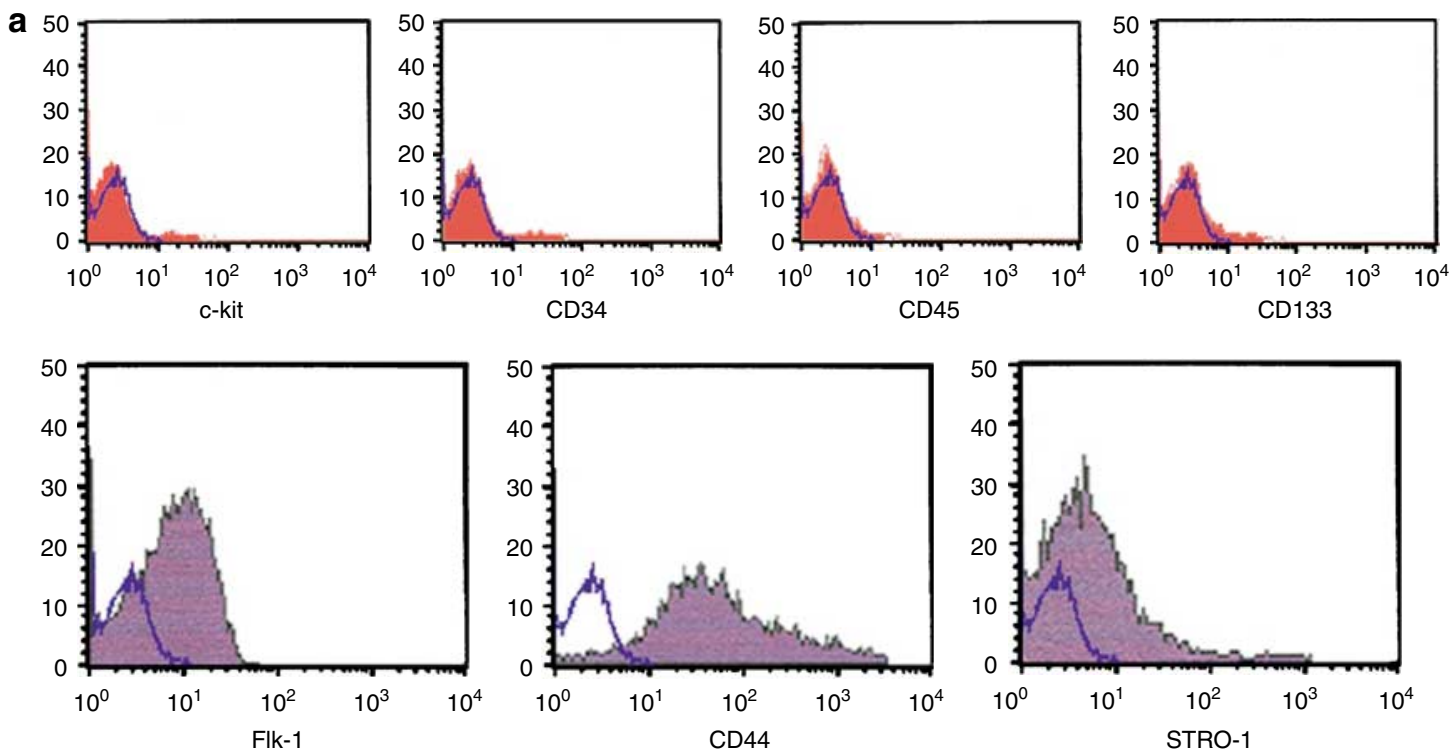

b
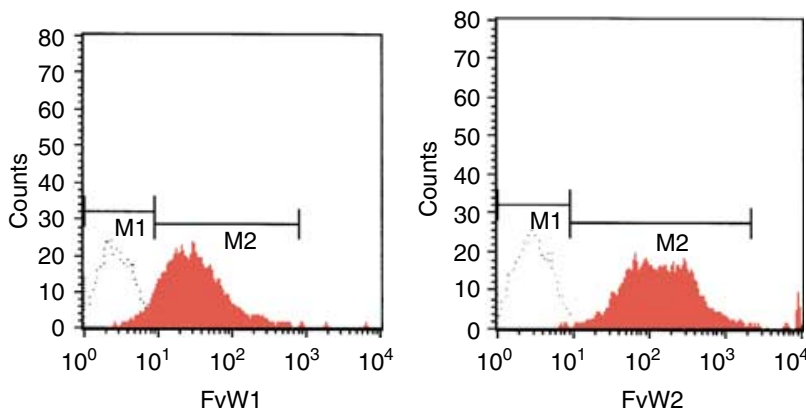

C
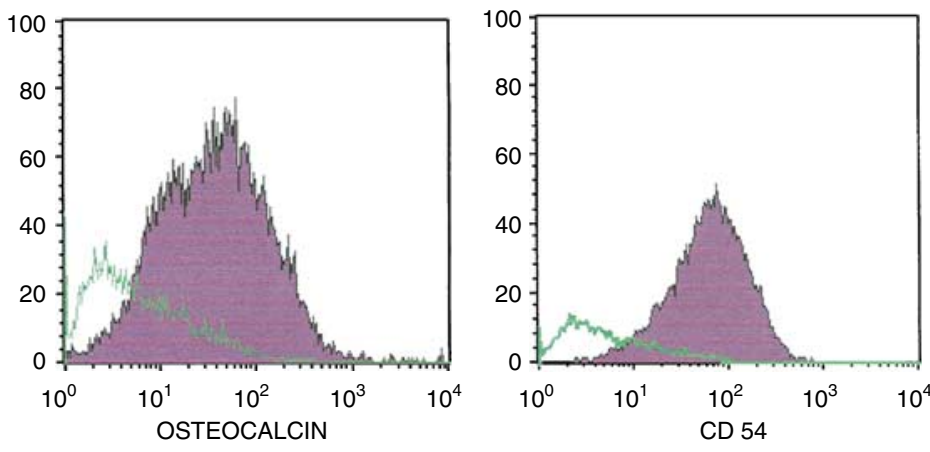
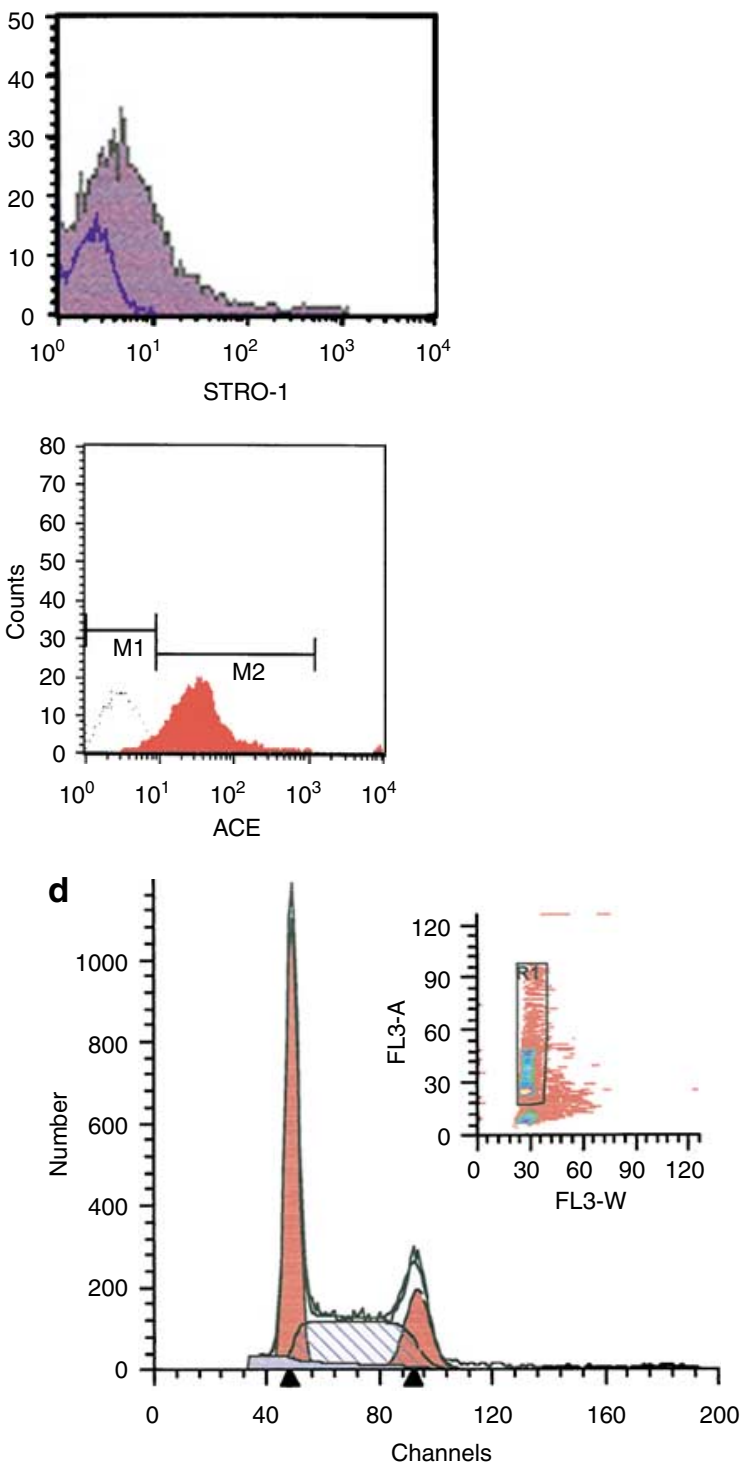

Figure 2 (a) Flow analysis at day 30, demonstrates flk-1, CD44 and STRO-1 positivity and CD117 (c-kit) CD34, CD90, CD133 and CD45 negativity (b) Flow analysis at day 45 evidencing von-Willebrand (domain 1-2) and ACE positivity (c) Flow analysis at day 40 evidencing osteocalcin and CD54 positivity (d) Cell cycle, performed at day 37 of culture, evidencing total S-phase cells were of about $38 \%$ and that all cells were still euploid

evidenced that these cells were osteoblasts and that they were very similar to those usually seen when these cells are involved during in vivo osteogenesis. The other cytotype had a flat appearance, were polygonal and elongated in shape with a central discoid nucleus (Figure 6d). The cytoplasm was considerably reduced at the cell periphery. Within the cytoplasm, endocytotic vesicles were observed and in some cases, these cells of endothelial appearance, were close to each other, arranged in parallel layers. Immunofluorescence observations showed that within the bone chips some cells were positive for CD31 (PECAM-1) (Figure 6e), which is the ligand for CD38 (usually and strongly expressed in endothelial cells that play a role in angiogenesis), for ACE (Figure 6f), and for von-Willebrand 

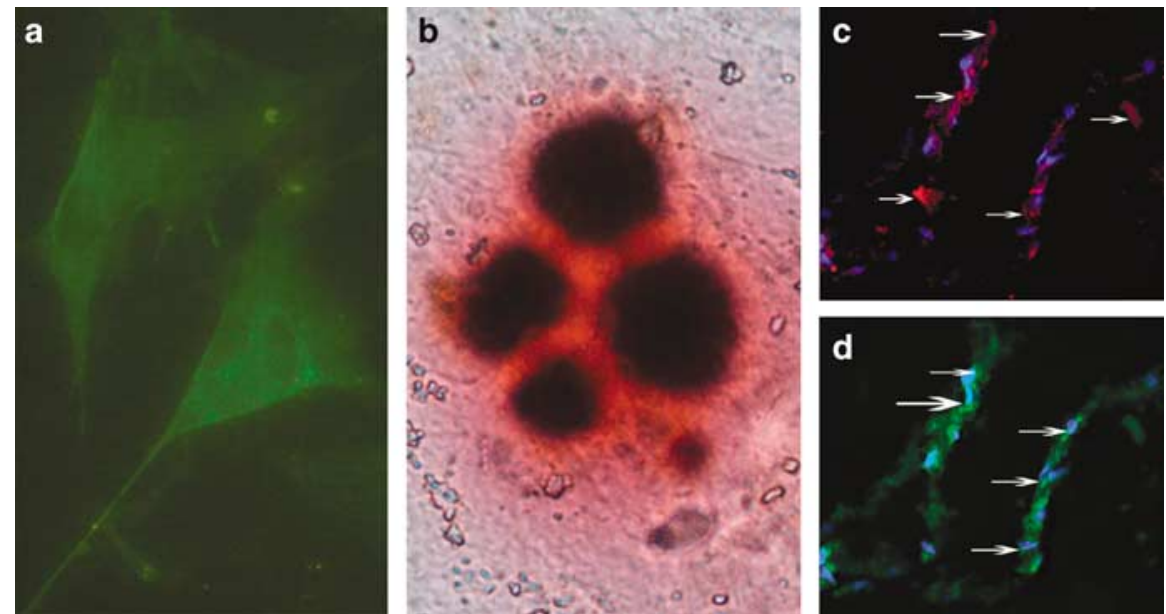

Figure 3 (a) Stem cells differentiated into (a) smooth muscle cells, showing positivity for SMA (original magnification $\times 200$ ) (b) adipocytes, showing positivity for Oil-red0 staining (original magnification $\times 200$ ); (c) neuronal cells, showing positivity for Tuj-1 (arrows) (original magnification $\times 200$ ) and (d) for Brn 3a (arrows) (original magnification $\times 200)$

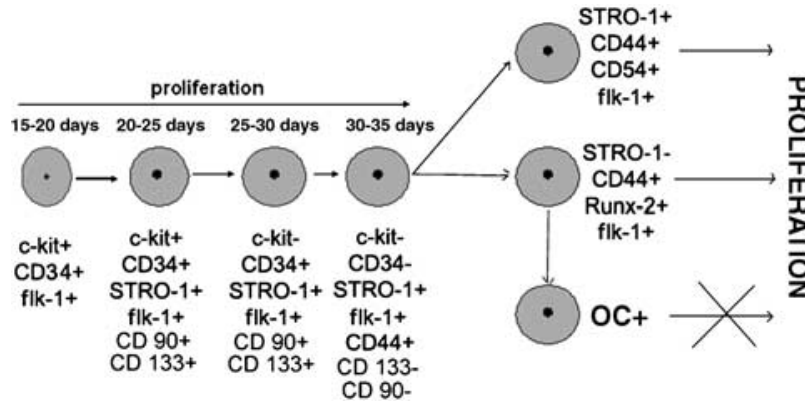

Figure 4 Antigenic kinetic pattern of stem and differentiated cells

(domains 1 and 2). These cells formed the wall of several round or oval vessels within each bone chip.

In vivo transplantation. Results show that in all groups, both woven bone chips and cells upon scaffolds become adult bone. Dimensions obtained were the same as the transplanted woven chips or of that of the transplanted scaffold, in the case of cells. This bone was intensely positive for alizarin red as well as for the complete panel of bone markers, including BAP, osteocalcin, osteonectin and BSP (Figure 7a, b, c, d). Interestingly, $\mathrm{HLA}-1^{+}$vessels were found in all cases, both within the tissue and on its borders. Those were also positive for von-Willebrand 1/2 (Figure 7e) and PECAM-1 (Figure 7f). This remarkable result is further emphasized by the fact that $\mathrm{HLA}-1^{+}$vessels (therefore, of human origin), were of different dimensions and contained host blood (Figure $7 \mathrm{~g}, \mathrm{~h}$ ), demonstrating that the transplants were completely and efficiently integrated within the host.

\section{Discussion}

SBP-DPSCs, representing roughly $10 \%$ of dental pulp cells display multipotency; in fact, they differentiate into smooth muscle cells, adipocytes, neurons and osteoblasts. Osteoblastic differentiation was substantiated by the expression of
RUNX-2, a transcription factor essential for inducing osteoblast differentiation. ${ }^{13-16}$ Cell cycle analysis showed that differentiated cells contained a higher percentage of cells in S phase $(38 \%)$ with respect to undifferentiated cells.

When SBP-DPSCs differentiated into osteoblasts, they gave rise also to endotheliocytes. Both cytotypes concur and are of paramount importance for the production of woven bone in vitro, as we have shown.

During their differentiation, SBP-DPSCs were observed to change their surface antigen expression. At day 40, starting from a common flk- $1^{+} / \mathrm{STRO}-1^{+} / \mathrm{CD} 44^{+}$progenitor, stem cells started to differentiate into two cytotypes: about $70 \%$ of them became osteogenic progenitor cells, being $\mathrm{flk}-1^{+} /$ STRO $-1^{-} / \mathrm{CD} 44^{+} / \mathrm{RUNX}-2^{+}$, whereas the remaining $30 \%$ became flk- $1^{+} / \mathrm{STRO}-1^{+} / \mathrm{CD} 44^{+} / \mathrm{CD} 54^{+}$endothelial cells. Cytofluorimetric data were substantiated by semiquantitative RT-PCR analysis.

At day 45 of culture, osteocalcin positive cells were detected within the flk-1 ${ }^{+} / \mathrm{STRO}-1^{-} / \mathrm{CD} 44^{+} / \mathrm{RUNX}-2^{+}$ population. This positivity, as well as that for BAP and BSP, as well as their ultrastructural appearance, confirmed that these cells were osteoblasts. Interestingly, these cells were always negative for DSPP, a marker of dentin, stressing that the hard tissue they produce is bone and not dentin.

As already pointed out, differentiated cells within the woven bone chips were $\mathrm{CD}_{54}{ }^{+}$, an antigen specifically expressed by endotheliocytes. ${ }^{17}$ These cells were diffusely positive for other markers of endothelia, including von-Willebrand domains 1 and $2^{18-19}$ and ACE. ${ }^{20}$ They were found lining the vessel walls of the newly formed woven bone. This observation is of importance because it indicates that a process of vasculogenesis takes place in vitro within the newly synthesized tissue. As shown by immunofluorescence analysis performed on bone chips, ACE positive cells coexpressed CD31 within the wall of vascular formations. Ultrastructural observations confirmed that endothelial cells were present within bone chips. The formation of vessels explains the vitality of bone chips when transplanted in immunosuppressed rats. ${ }^{5,6}$ 

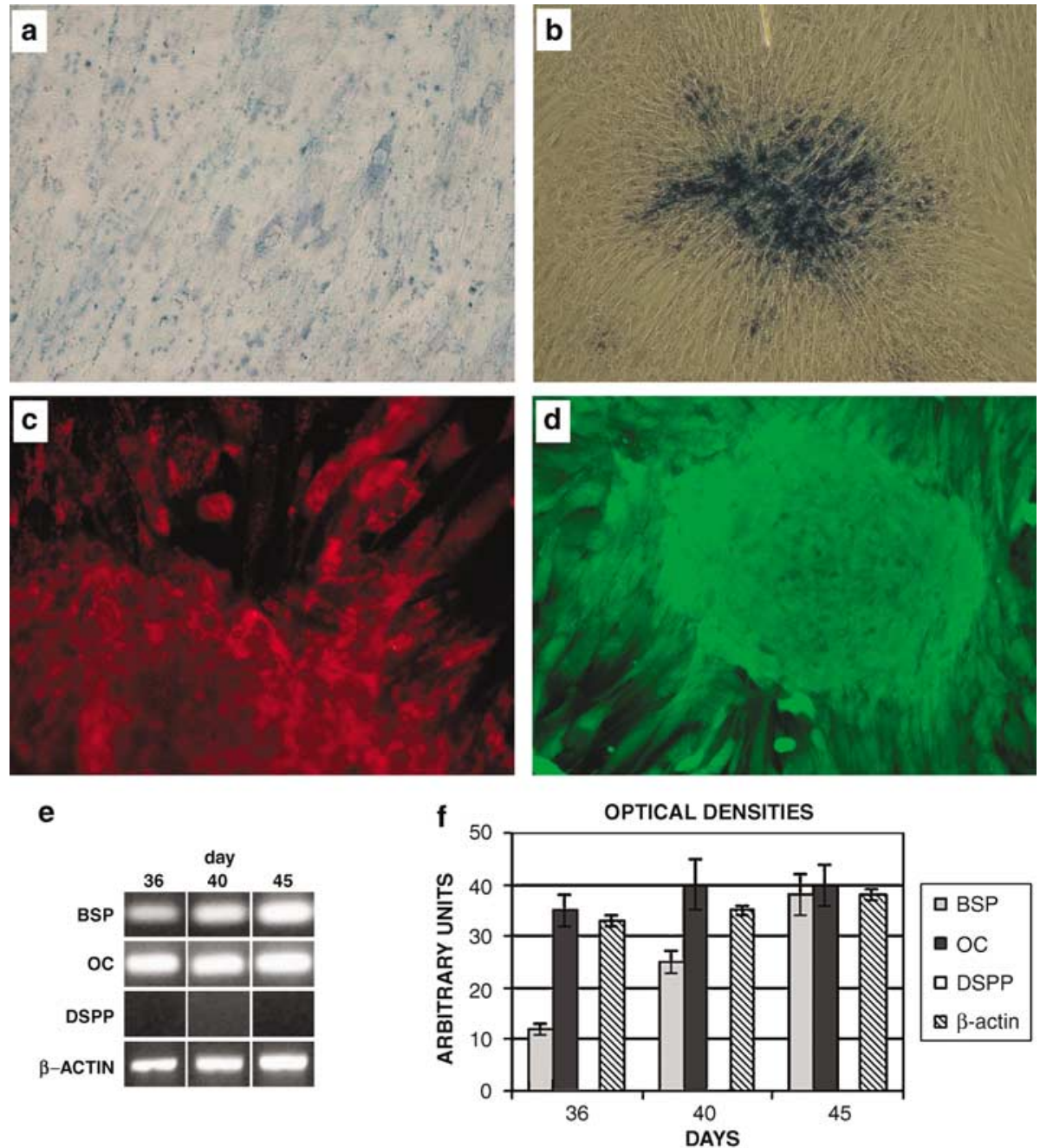

Figure 5 (a) ALP histochemistry of undifferentiated cells: positivity is largely diffuse (original magnification $\times 200$ ); (b) ALP histochemistry detection on differentiated cells: positivity is localized at the level of calcified nodules (original magnification $\times 100$ ); (c) Immunofluorescence staining showing BAP-positive cells and extracellular deposits on calcified nodules (original magnification $\times 400$ ); (d) Calcein-positive differentiated cells with extracellular calcium deposits on calcified nodules (original magnification $\times 400$ ); (e) RT-PCR analysis of osteocalcin, BSP and DSPP performed on differentiated osteoblasts within the bone tissue performed at days 36,40 and 45; (f) Semiquantitative analysis of RT-PCR. Optical quantification of band intensities was obtained with an Ultrascan Enhancer Laser Densitometer. OD is expressed in arbitrary units \pm S.D. of repeat numbers

$\mathrm{flk}-1^{+}$exerts a pivotal role in coupling osteoblast and endotheliocyte differentiation, as previously hypothesized $^{21-23}$ and the intimate relationship and interplay between endotheliocytes and osteoblasts is the key to obtain complete differentiation and formation of mature bone.

In this study, we have also demonstrated another functional property of these cells related to the expression of ALP. Actually, while stem cells expressed 'nonspecific' ALP activity, differentiated cells expressed a 'specific' BAP. This switching of enzyme activity is due to the fact that in stem cells, ALP exerts activities aimed at maintaining cell homeostasis. On the other hand, in osteoblast-differentiated cells, BAP specifically mineralizes the pre-secreted organic matrix. This is assessed by different localization and immunofluorescence positivity; in fact, whereas 'nonspecific' ALP was diffusely expressed, 'specific' ALP (BAP) was only expressed in ossification centres.

Data from transplantation studies are of extreme interest for therapeutic use. In fact, here we show that both woven chips and stem cells grown on a scaffold, became adult bone after transplantation. These structures were vascularized, and vessels were of human origin and contained host blood. Blood vessels were found in Haver's channels surrounded by bone arranged in a lamellar configuration. This is the first demonstration that vascularized bone can be obtained from stem cells.

In conclusion, our study provides evidence that DPSCs represent a population of postnatal stem cells that, when differentiated into osteogenic progenitors, change their antigen surface expression and morphology. These cells give rise to osteoblasts and endotheliocytes, and eventually to bone containing vessels, capable of forming an adult bone tissue after transplantation in vivo. The presence of vessels and their complete integration with the host is of great importance for its use in therapy. Therefore, this is a model of synergic differentiation, whose key aspect is the expression of flk-1, pivotal for the coupling of osteogenesis and vasculogenesis. 

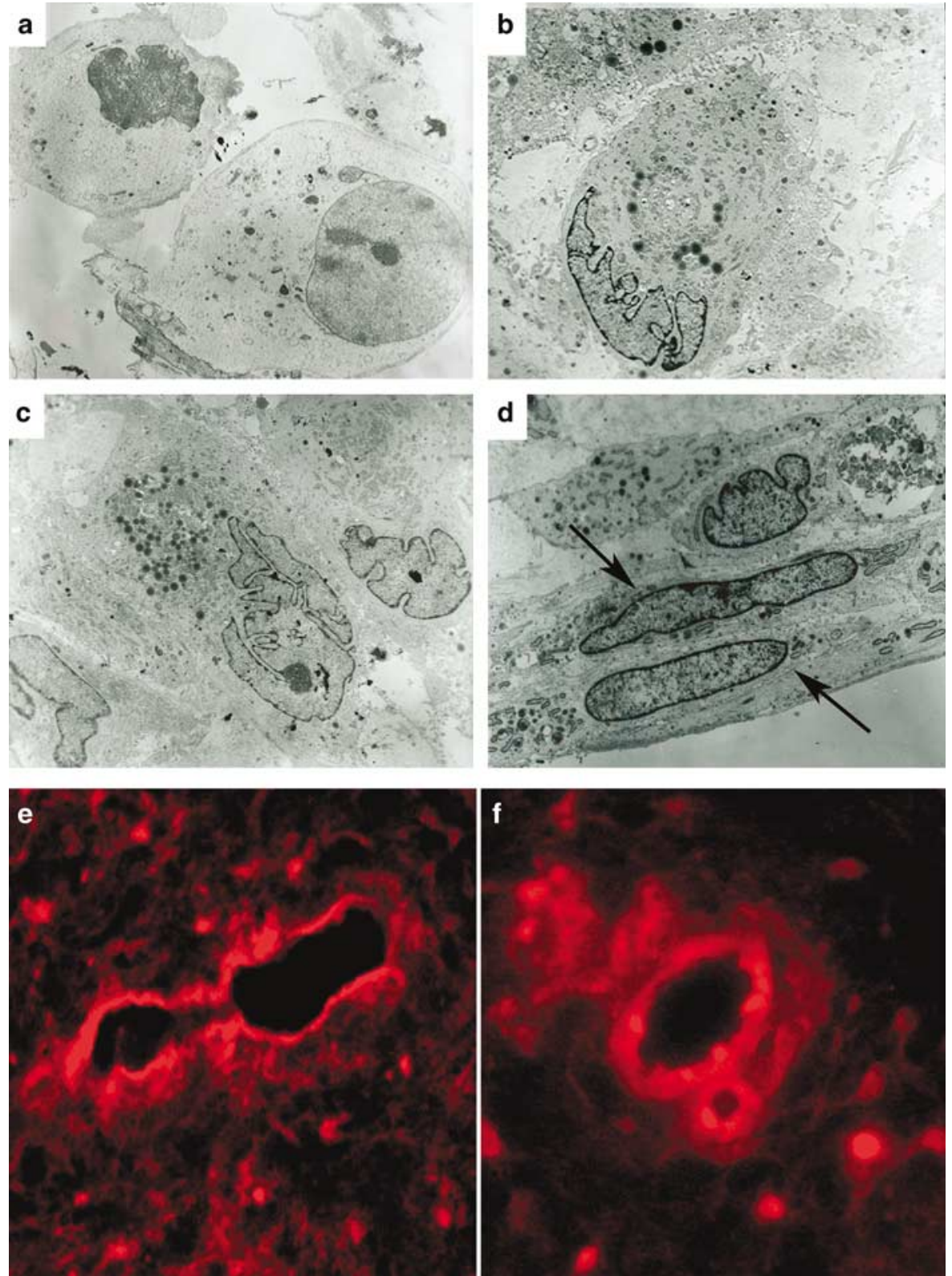

Figure 6 (a) Ultrastructural appearance of stem cells at day 22: cells are round in shape, with a basal nucleus showing one or two nucleoli and a thin nuclear elongations; the cytoplasm contains rudimental cysternae of reticulum, scattered lysosome-like organelles and elongated mitochondria. (original magnification $\times 3600$ ). (b) Ultrastructure of differentiated cells with nuclear polarity, at day 60 , showing a cuboidal shape, with a basal nucleus, an evident nucleolus and an extremely extended rough endoplasmic reticulum with enlarged cysternae, a rather large Golgi apparatus and numerous coated matrix vesicles. (original magnification $\times 2800$ ). (c) Ultrastructural appearance of a single monolayer of osteoblasts, which are close to each other, with a basal (polar) nucleus (original magnification $\times 2800$ ). (d) Ultrastructural appearance of endothelial cells (arrows), showing an elongated shape (original magnification $\times 2800$ ). (e) Immunofluorescence showing CD31 (PECAM-1)-positive (arrow) endothelial cells forming a vessel wall, within the woven bone. (f) Immunofluorescence showing ACE positive endothelial cells within the woven bone

The latter also represents an interesting aspect for development and a complete and efficient three-dimensional tissue reconstruction therapy.

\section{Materials and Methods}

Dental pulp extraction and digestion. Human dental pulp was extracted from teeth of healthy adults following our protocol. ${ }^{3,4}$ Before extraction, each subject was checked for systemic and oral infection or diseases. Only disease-free subjects were selected. Each subject was pretreated for a week with professional dental hygiene. Before extraction, the dental crown was covered with $0.3 \%$ chlorexidin gel
(Forhans, NY, USA) for 2 min and then pulp was extracted with a dentinal excavator or a Gracey curette. Once removed, the pulp was immersed in a digestive solution ( $3 \mathrm{mg} / \mathrm{ml}$ type I collagenase plus $4 \mathrm{mg} / \mathrm{ml}$ dispase in $4 \mathrm{ml} 1 \mathrm{M} \mathrm{PBS}$, containing $100 \mathrm{U} /$ $\mathrm{ml}$ penicillin, $100 \mu \mathrm{g} / \mathrm{ml}$ streptomycin and $0.6 \mathrm{ml}$ claritromycin $(500 \mu \mathrm{g} / \mathrm{ml})$ for $1 \mathrm{~h}$ at $37^{\circ} \mathrm{C}$. The solution was then filtered with $70 \mu \mathrm{m}$ Falcon strainers (Becton and Dickinson, Franklin Lakes, NJ, USA).

Cell culture. After filtration, cells were immersed in MegaCell culture medium (Sigma, Milan, Italy) supplemented with 10\% FBS, $100 \mu \mathrm{M}$ 2P-ascorbic acid, $2 \mathrm{mM}$ L-glutamine, $100 \mathrm{U} / \mathrm{ml}$ penicillin, $100 \mu \mathrm{g} / \mathrm{ml}$ streptomycin (all purchased from Invitrogen, San Giuliano Milanese, Milan, Italy) and placed in $75 \mathrm{ml}$ flasks with 

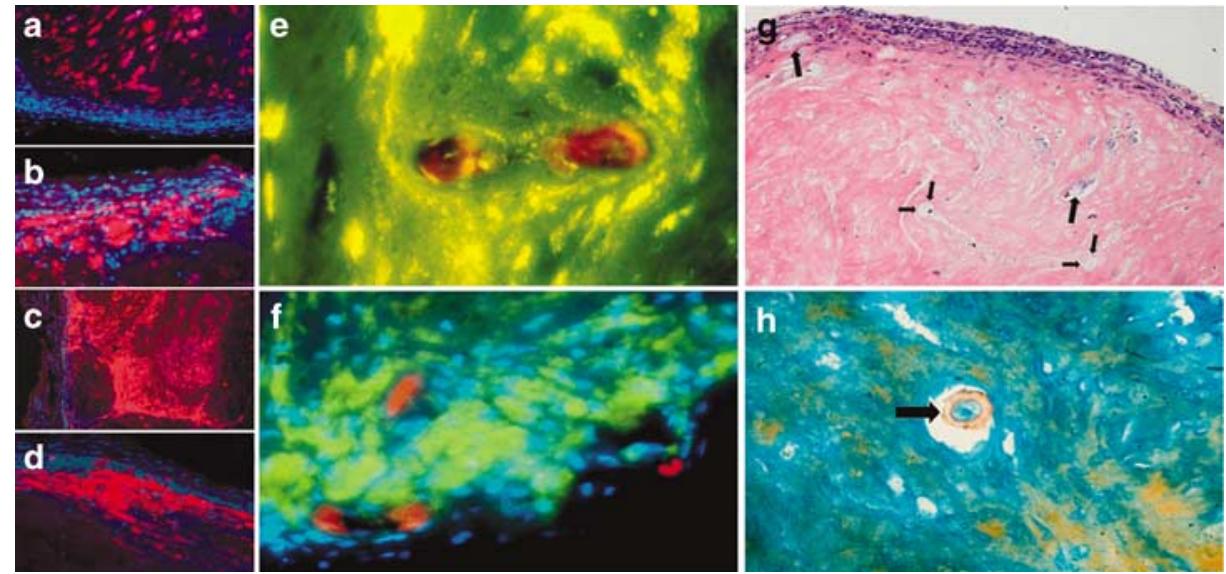

Figure 7 Bone sample obtained after 45 days of transplantation shows an intense positivity for: (a) BAP (DAPI counterstained; original magnification $\times 200)$, (b) for osteocalcin (DAPI counterstained; original magnification $\times 200$ ), (c) for Osteonectin (DAPI counterstained; original magnification $\times 100)$; (d) for BSP (DAPI counterstained; original magnification $\times 200$ ); (e) HLA-1 and von-Willebrand $1 / 2$ (double-stained)-positive vessels within the bone obtained after 30 days of transplantation. Vessels, surrounded by mineralized extracellular matrix, mimic bone Haver's channels (original magnification $\times 400$ ); (f) HLA-1 and PECAM-1 (double-stained)-positive vessels within and around the bone obtained after 60 days of transplantation (original magnification $\times 200$ ); (g) Bone section belonging to a sample obtained after 60 days of transplantation, showing vessels (arrows) within and around the tissue. (hematoxylin and eosin stain) (original magnification $\times 100$ ); (h) Bone section belonging to a sample obtained after 60 days of transplantation, showing a vessel (arrow) within the tissue. (Mallory stain) (original magnification $\times 400$ )

filtered valves. Flasks were incubated at $37^{\circ} \mathrm{C}$ and $5 \% \mathrm{CO}_{2}$ and the medium changed twice a week. Just before cells become confluent, they were subdivided into new flasks. From 16 to 20 passages were performed.

Stem cells were sorted (see below) only when their number was at least 1000000 per flask. This number was achieved around day 22, when they were still undifferentiated. Differentiated cells were obtained from sorted stem cells cultured for at least 30 days in $\alpha$-MEM culture medium with 20\% FBS (all purchased from Invitrogen, San Giuliano Milanese, Milan, Italy); in fact, FBS exerts a differentiation activity favoring osteoblastic differentiation when used in high percentage. ${ }^{5,6}$

FAC analysis and sortings. Cells were detached using $0.02 \%$. EDTA solution in PBS and collected (10 min at 1,000 r.p.m.), washed in $0.1 \%$ BSA in PBS at $4{ }^{\circ} \mathrm{C}$, then incubated in a solution of $1 \mu \mathrm{l}$ antibody $/ 9 \mu \mathrm{l} 0.1 \%$ BSA in PBS. Cells were then washed in the same solution (see above) and were ready for observation. Antibodies used for sorting were the following mouse anti-human antibodies: CD117 (c-kit) (Santa Cruz, CA, USA), CD34 (MBL, Woburn, MA, USA), flk-1 (Santa Cruz, CA, USA) and STRO-1 (Dr Torok-Storb through DBA, Segrate, Milan, Italy). We sorted using both morphological (high side scatter and low forward scatter) and antigenic criteria (first with CD117 and CD34 and then, serially for STRO-1 and flk1). We selected only cells that expressed all these markers in order to obtain a homogeneous population.

After sorting, with the same procedures, we analyzed the sorted cells with antiCD45 (Santa Cruz, CA, USA), anti-CD90 (Santa Cruz, CA, USA) and anti-CD133 (Miltenyi Biotec $\mathrm{GmbH}$, Gladbach, Germany).

After differentiation, cells were examined for the following antibodies, other than the previous antibodies for stem cell markers, in order to assess osteogenic differentiation: CD54, CD44 (MBL, Woburn, MA, USA), Osteocalcin (Santa Cruz, CA, USA) and the transcription factor RUNX-2 (Santa Cruz, CA, USA). For RUNX-2 analysis cells were fixed in $4 \%$ paraformaldehyde in $1 \mathrm{M}$ PBS, with $0.2 \%$ Triton X100 for 30 min at $4{ }^{\circ} \mathrm{C}$, washed twice in $0.1 \%$ BSA in $1 \mathrm{M} \mathrm{PBS}$ and then incubated with RUNX-2 antibody. To asses endothelial differentiation the following antibodies were used: CD31 (PECAM-1) (Santa Cruz, CA, USA), von-Willebrand (domain 1 and 2) (kind gift of Dr Massimo Ragni, School of Medicine, University 'Federico II' Naples Italy); ACE (kind gift of Dr. Massimo Ragni).

Colony efficiency assays and proliferation potential. To evaluate colony efficiency and proliferation potential of sorted stem cells, single cells obtained by limiting dilutions were plated. Numbers of clones and cells were evaluated. After three weeks of culture, cells were stained with $0.1 \%(\mathrm{v} / \mathrm{v})$ toluidine blue in $1 \%$ paraformaldehyde. The number of clones ( $>50$ cells) were counted.
Smooth muscle, neural and adipocyte differentiation. Sorted cells were challenged to assess their multipotency. For smooth muscle differentiation, cells were cultured in the presence of $2 \%$ FBS and $10 \mathrm{ng} / \mathrm{ml} \beta$-TGF for $4-6$ days. For neural differentiation, cells were cultured at high densities, spontaneously forming spherical clumps of cells that were isolated with $0.25 \%$ trypsin (Invitrogen). Free-floating neurospheres that were released from the cell culture surface into the culture media were also collected. The spheres of cells were transferred to a Petri dish and cultured in Neurobasal medium (Invitrogen, Milan, Italy) supplemented with B27 (Invitrogen), $20 \mathrm{ng} / \mathrm{ml} \mathrm{bFGF,} \mathrm{and} 20 \mathrm{ng} / \mathrm{ml}$ EGF (Sigma, Milan, Italy) for 4-7 days. The culture density of the spheroid bodies was maintained at $10-20$ cells $/ \mathrm{cm}^{2}$ to prevent self aggregation. For adipocyte differentiation, the culture medium was supplemented with $10 \%$ FBS and $10^{-8} \mathrm{M}$ dexamethasone twice a week for six weeks. Oil red-O staining was used to identify lipid-laden fat cells. All the experiments were made in quadruplicate.

Cell cycle analysis. Cell cycle was analyzed by flow cytometry. Cells were harvested in phosphate-buffered saline (PBS) containing $2 \mathrm{mM}$ EDTA, washed once with PBS and lysed with hypotonic DNA staining solution (0.1\% Triton X-100, $0.1 \%$ sodium citrate, $1 \mathrm{mg} / \mathrm{ml}$ RNAse $A$ and $50 \mu \mathrm{g} / \mathrm{ml}$ propidium iodide) for $2 \mathrm{~h}$ at room temperature in the dark.

Stained nuclei were analyzed with a fluorescence-activated cell sorter (FACS) Vantage (Becton-Dickinson) and the data were analyzed using a Mod-Fit cell cycle analysis program (Becton-Dickinson). Analyses were performed in four's for each sample and time from day 15 up to the 45th day of culture.

Histochemistry. For alkaline phosphatase (ALP), cells and tissue samples, were washed in PBS and fixed in $4 \%$ paraformaldehyde in PBS, with $0.2 \%$. Triton $\mathrm{X} 100$ for $30 \mathrm{~min}$ at $4^{\circ} \mathrm{C}$, then washed twice in $0.1 \%$ BSA in PBS at room temperature for 10 min each. ALP activity was measured using 100000 cells/ sample, detached with PBS/EDTA $0.02 \%$ and centrifuged for $10 \mathrm{~min}$ at $140 \mathrm{~g}$. The pellet was incubated with $1 \mathrm{ml}$ of BMPurple solution (Roche, Segrate, Milan, Italy) for $8 \mathrm{~h}$ in the dark. Supernatant was read in a spectrophotometer at $615 \mathrm{~nm}$. As control, c-kit ${ }^{-} /$STRO-1-/CD34- ${ }^{-}$cells were used. The values were expressed as the ratio of sample and BMPurple stock solution. BMPurple solvent was used as blank.

For calcein staining, a solution of $50 \mu \mathrm{M}$ calcein-AM in PBS (Dojindo Molecular Technologies, Gaithersburg, MD, USA), was added to culture medium (1/10 v/v). After incubation at $37^{\circ} \mathrm{C}$ with $5 \% \mathrm{CO}_{2}$ for $30 \mathrm{~min}$, cells were washed twice with PBS. The observation was performed using a fluorescence microscope with $490 \mathrm{~nm}$ excitation and $512 \mathrm{~nm}$ emission filters. 


\begin{tabular}{|c|c|c|c|c|c|c|}
\hline \multirow[b]{2}{*}{ RAT } & \multicolumn{2}{|c|}{30 days } & \multicolumn{2}{|c|}{45 days } & \multicolumn{2}{|c|}{60 days } \\
\hline & Site 1 & Site 2 & Site 1 & Site 2 & Site 1 & Site 2 \\
\hline $\begin{array}{l}1 \\
2 \\
3 \\
4 \\
5 \\
6 \\
7 \\
8 \\
9\end{array}$ & $\begin{array}{l}\text { Scaffold } \\
\text { Scaffold+stem } \\
\text { Bone chips } \\
\text { Scaffold+stem } \\
\text { Bone chips } \\
\text { Scaffold+stem } \\
\text { Bone chips } \\
\text { Scaffold } \\
\text { Scaffold }\end{array}$ & $\begin{array}{l}\text { Scaffold+stem } \\
\text { Scaffold } \\
\text { Scaffold+stem } \\
\text { Bone chips } \\
\text { Scaffold+stem } \\
\text { Scaffold } \\
\text { Scaffold } \\
\text { Scaffold+stem } \\
\text { Scaffold }\end{array}$ & $\begin{array}{l}\text { Scaffold } \\
\text { Scaffold+stem } \\
\text { Bone chips } \\
\text { Scaffold+stem } \\
\text { Bone chips } \\
\text { Scaffold+stem } \\
\text { Bone chips } \\
\text { Scaffold } \\
\text { Scaffold }\end{array}$ & $\begin{array}{l}\text { Scaffold+stem } \\
\text { Scaffold } \\
\text { Scaffold+stem } \\
\text { Bone chips } \\
\text { Scaffold+stem } \\
\text { Scaffold } \\
\text { Scaffold } \\
\text { Scaffold+stem } \\
\text { Scaffold }\end{array}$ & $\begin{array}{l}\text { Scaffold } \\
\text { Scaffold+stem } \\
\text { Bone chips } \\
\text { Scaffold+stem } \\
\text { Bone chips } \\
\text { Scaffold+stem } \\
\text { Bone chips } \\
\text { Scaffold } \\
\text { Scaffold }\end{array}$ & $\begin{array}{l}\text { Scaffold+stem } \\
\text { Scaffold } \\
\text { Scaffold+stem } \\
\text { Bone chips } \\
\text { Scaffold+stem } \\
\text { Scaffold } \\
\text { Scaffold } \\
\text { Scaffold+stem } \\
\text { Scaffold }\end{array}$ \\
\hline
\end{tabular}

Immunofluorescence. Bone tissue samples were embedded in TBS (tissue freezing medium, Triangle Biomedical Sciences, Durham, NC, USA) and cryosectioned (Cryostat 1720 Digital MGW Lauda, Leika, Germany), fixed in $100 \%$ ethanol for $30 \mathrm{~min}$ at $4^{\circ} \mathrm{C}$, washed in PBS, then left for $60 \mathrm{~min}$ in $6 \% \mathrm{milk} / \mathrm{PBS}$. Osteogenic differentiation was evaluated using the following antibodies: monoclonal BAP (US Biological, USA), mouse anti-human, monoclonal BSP mouse anti-human (Chenicon International, Prodotti Gianni, Milan, Italy), monoclonal osteonectin mouse anti-human (Novocastra Laboratories, Ltd, UK) and polyclonal osteocalcin (Santa Cruz, CA, USA) goat anti-human. The secondary antibodies were goat antimouse (FITC) and mouse anti goat (PE conjugated) (Santa Cruz, CA, USA).

Neo-vasculogenesis within the LAB chips was evaluated using anti-CD31 (PECAM-1) (Santa Cruz), anti-von-Willebrand (domain 1 and 2) and anti- ACE (kind gifts of Dr Massimo Ragni, School of Medicine, University 'Federico II', Naples Italy) all mouse anti-human. The secondary antibody was goat anti-mouse (FITC and PE) (Santa Cruz, DBA, Milan, Italy).

Stem cell differentiation toward other cytotypes was evaluated as follows: smooth actin mouse anti-human antibody (Chemicon International, Prodotti Gianni, Milan, Italy) to confirm smooth muscle differentiation. The secondary antibody was goat anti-mouse (FITC; Santa Cruz, CA, USA); neural differentiation was evaluated using a marker of neuronal class III $\beta$ tubulin, Tuj-1, a mouse anti-human antibody (Covance, Berkeley, CA, USA) and anti-Brn $3 a$ (a transcription factor), that is a mouse anti-human antibody (Santa Cruz, CA, USA). The secondary antibody was goat anti-mouse (FITC; Santa Cruz, CA, USA). Isotypes and non-probed cells were used as controls. Incubation with antibodies was performed at $4^{\circ} \mathrm{C}$ overnight. In addition, to evaluate cell distribution, in both cells and tissue, a DAPI counterstaining was performed.

Cells or tissue sections were washed twice as described above (PBS, $60 \mathrm{~min}$ in $6 \%$ milk/PBS and then $10 \mathrm{~min}$ in PBS only) and observed under the microscope (Fluorescence microscope BX-41, Olympus Optical Co. Europe, Hamburg, Germany).

Reverse transcriptase polymerase chain reaction analysis. Total RNA was extracted from 1000000 cells at each time point (day 15, 22, 30 and 36 for CD117, CD34 and flk-1, or day 36, 40 and 45 for osteocalcin, BSP and DSPP), by homogenization in TRI Reagent (Sigma, Milan, Italy), following the manufacturer's instructions and stored at $-70^{\circ} \mathrm{C}$ until the assays. CDNA synthesis was carried out from total RNA using Superscript II reverse transcriptase (Invitrogen Celbio Italy, San Giuliano Milanese, Milan, Italy), using oligo (dT) $)_{12-18}$ and Moloney murine leukemia virus reverse transcriptase $(10 \mathrm{U} / \mu \mathrm{l})$ in $20 \mu \mathrm{l}$ at $42^{\circ} \mathrm{C}$ for $50 \mathrm{~min}$. PCR analyses were made in triplicate using a TC-312 thermal cycler (Techne, Burlington, NJ, USA), in which samples underwent to a 2 min denaturing step to $94^{\circ} \mathrm{C}$ followed by 35 cycles of $94^{\circ} \mathrm{C}$ for $30 \mathrm{~s}, 54^{\circ} \mathrm{C}$ for $45 \mathrm{~s}$, $72^{\circ} \mathrm{C}$ for $1 \mathrm{~min}$ and a final extension step at $72^{\circ} \mathrm{C}$ for $4 \mathrm{~min}$. The PCR mixture contained $0.2 \mathrm{mM}$ of each dNTP, $1.5 \mathrm{mM} \mathrm{MgCl}, 0.2 \mu \mathrm{M}$ of each primer. The primer sequences were: forward CD117 5'-TCTCCACCATCCATCCATCC-3'; reverse CD117 5'-ATTTTTCCGACAGCACTGAC-3'; forward CD34 5'-CCCAGTCTG AGGTGAGGCCT-3'; reverse CD34 5'-ACTCTAACTAGCGAGTAC AATTCGG-3'; flk-1 forward $5^{\prime}$-TTGGAGCATCTCATCTGTTACAGC- $3^{\prime}$ and reverse $5^{\prime}$ CTTTCG CTTACT-3'. Osteocalcin forward $5^{\prime}$-ctagcagacaccatgaggacc- $3^{\prime}$ reverse $5^{\prime}$ GGTCCTAAATAGTGATACCG-3'; forward BSP forward 5'-TGCCTTGAG CCTGCTTCCT $3^{\prime}$-reverse $5^{\prime}$ CTGAGCAAAATTAAAGCAGTCTTCA-3'; DSPP forward $5^{\prime}$-ATCACCAAAGAATCAGAGACAC- $3^{\prime}$ reverse DSPP $5^{\prime}$-AAGCAT CTCCTCGGCTAC- $3^{\prime} ; \beta$-actin forward $5^{\prime}$-TGTGATGGTGGGAATGGGTCAG-3'; reverse $\beta$-actin $5^{\prime}$-TTTGATGTCACGCACGATTTCC- $3^{\prime}$. The amplification products were separated on $2 \%$ agarose gel in Tris acetate EDTA buffer. Band intensities were quantified with an Ultrascan XL Enhancer Laser Densitometer (LKB, Bromma, Sweden) and expressed in arbitrary units of optical densities (OD) ( \pm S.D. of repeat numbers). PCRs were performed on RT-negative samples to exclude DNA contamination.

Ultrastructure. Cells and chips of the new-formed woven bone were fixed in $2.5 \%$. glutaraldehyde (EM grade) in a phosphate buffer, postfixed in $0.1 \% \mathrm{OsO}_{4}$ in the same buffered solution for $1 \mathrm{~h}$, then dehydrated and embedded in epoxy resins. Counterstained (uranyl acetate and lead citrate) ultrathin sections were observed under an electron microscope (Philips $400 \mathrm{~S}$, Eindhoven, The Netherlands).

In vivo transplantation experiments. Transplantation experiments were designed as follows: 4-week-old immunosuppressed rats (Wistar rats $n=27$, Charles River Laboratories Italia S.p. A., Calco, Lecco, Italy) were immunocompromised using Cyclosporine A (Sandman, Novelties S.p.A., Origin, Varies, Italy) at a dosage of $15 \mathrm{mg} / \mathrm{kg}$ body weight, administered $4 \mathrm{~h}$ before transplantation and then daily for 2 weeks. During the last 2 weeks, the daily dosage was reduced gradually up to $6 \mathrm{mg} / \mathrm{kg}$ body weight. Rats were subdivided into three groups (group 30, 45 and 60). Animals of each group were transplanted either with woven bone tissue samples (chips) obtained in vitro after 60 days of culture, each measuring approximately $1.5 \times 1 \mathrm{~cm}$, or with $200000 \mathrm{STRO}-1^{+} / \mathrm{CD} 34^{+} / \mathrm{flk}-1^{+} /$ $\mathrm{CD}^{+}{ }^{+} / \mathrm{CD} 133^{+}$cultured 30 -day-old cells on polymer scaffolds made of a three layer structure of trimethylene carbonate and lactide polyglycolic acid (Inion Ltd, Tampere, Finland). Transplants were performed in two subcutaneous sites of the dorsal surface of each animal. The scaffold alone was used as control. Table 1 summarizes the transplantation design. Grafts were recovered respectively at 30 , 45 and 60 days after transplantation, fixed with $4 \%$ formalin, and then embedded in paraffin. Sections ( $7 \mu \mathrm{m}$ thick) were deparaffinized and stained with haematoxylineosin, Mallory trichromic or used for immunofluorescence using HLA-1, vonWillebrand-1/2, PECAM-1, osteocalcin, BSP, BAP and osteonectin. Samples were observed under a Olympus BX-41 fluorescence microscope (Hamburg, Germany). All the above-mentioned procedures were approved by our internal small animal ethic committee.

Acknowledgements. This study was supported by 2nd University of Naples (2002/03 to GP), MIUR (Project of relevant interest 2005 to GP).

1. Calvi LM, Adams GB, Weibrecht KW, Weber JM, Olson DP, Knight MC et al. Osteoblastic cells regulate the haematopoietic stem cell niche. Nature 2003; 425: 841-846.

2. Zhang J, Niu C, Ye L, Huang H, He X, Tong WG et al. Identification of the haematopoietic stem cell niche and control of the niche size. Nature 2003; 425: 836-840.

3. Gronthos S, Mankani M, Brahim J, Robey PG, Shi S. Postnatal human dental pulp stem cells (DPSCs) in vitro and in vivo. Proc Natl Acad Sci USA 2000; 97: 13625-13630.

4. Miura M, Gronthos S, Zhao M, Lu B, Fisher LW, Robey PG et al. SHED: stem cells from human exfoliated deciduous teeth. Proc Natl Acad Sci USA 2003; 100: 5807-5812. 
5. Laino G, d'Aquino R, Graziano A, Lanza V, Carinci F, Naro F et al. A new population of human adult dental pulp stem cells: a useful source of living autologous fibrous bone tissue (LAB). J Bone Mineral Res 2005; 20: 1394-1402.

6. Laino G, Graziano A, d'Aquino R, Pirozzi G, Lanza V, Valiante S et al. An approachable human adult stem cell source for hard-tissue engineering. J Cell Physiol 2006; 206 693-701.

7. Pittenger MF, Mackay AM, Beck SC, Jaiswal RK, Douglas R, Mosca JD et al. Multilineage potential of adult human mesenchymal stem cells. Science 1999; 284 143-147.

8. Saito N, Okada T, Horiuchi H, Muratami N, Takahashi J, Nawata M et al. A biodegradable polymer as a cytokine delivery system for inducing bone formation. Nat Biotecnol 2001; 19 : 332-335.

9. Saito N, Okada T, Horiuchi H, Ota H, Takahashi J, Murakami N et al. Local bone formation by injection of recombinant human bone morphogenetic protein-2 contained in polymer carriers. Bone 2003; 32: 381-386.

10. de Oliveira PT, Nanci A. Nanotexturing of titanium-based surfaces upregulates expression of bone sialoprotein and osteopontin by cultured osteogenic cells. Biomaterials 2004; 25 : 403-413.

11. Gugala Z, Gogolewski S. The in vitro growth and activity of sheep osteoblasts on threedimensional scaffolds from poly(L/DL-lactide) 80/20\%. J Biomed Mater Res A 2005; 75 702-709.

12. Schantz JT, Brandwood A, Hutmacher DW, Khor HL, Bittner K. Osteogenic differentiation of mesenchymal progenitor cells in computer designed fibrin-polymer-ceramic scaffolds manufactured by fused deposition modeling. J Mater Sci Mater Med 2005; 16 807-819

13. Komori T, Yagi H, Nomura S, Yamaguchi A, Sasaki K, Deguchi K et al. Targeted disruption of Cbfa1 results in a complete lack of bone formation owing to maturational arrest of osteoblasts. Cell 1997; 89: 755-764.
14. Otto F, Thornell AP, Crompton T, Denzel A, Gilmour KC, Rosewell IR et al. Cbfa1, a candidate gene for cleidocranial dysplasia syndrome, is essential for osteoblast differentiation and bone development. Cell 1997; 89: 765-771.

15. Ducy P, Schinke T, Karsenty G. The osteoblast: a sophisticated fibroblast under central surveillance. Science 2000; 289: 1501-1504.

16. Harada S, Rodan GA. Control of osteoblast function and regulation of bone mass. Nature 2003; 423: 349-355.

17. Thompson PW, Randi AM, Ridley AJ. Intercellular adhesion molecule (ICAM)-1, but not ICAM-2, activates RhoA and stimulates c-fos and rhoA transcription in endothelial cells. $\mathrm{J}$ Immunol 2002; 169: 1007-1013.

18. Chalajour F, Treede H, Ebrahimnejad A, Lauke H, Reichenspurner H, Ergun S. Angiogenic activation of valvular endothelial cells in aortic valve stenosis. Exp Cell Res 2004; 298: 455-464.

19. Trojan L, Thomas D, Friedrich D, Grobholz R, Knoll T, Alken P et al. Expression of different vascular endothelial markers in prostate cancer and BPH tissue: an immunohistochemical and clinical evaluation. Anticancer Res 2004; 24: 1651-1656.

20. Bauvois $B$. Transmembrane proteases in cell growth and invasion: new contributors to angiogenesis? Oncogene 2004; 23: 317-329.

21. Wang DS, Miura M, Demura H, Sato K. Anabolic effects of 1,25-dihydroxyvitamin D3 on osteoblasts are enhanced by vascular endothelial growth factor produced by osteoblasts and by growth factors produced by endothelial cells. Endocrinology 1997; 138: 2953-2962.

22. Deckers MM, van Bezooijen RL, van der Horst G, Hoogendam J, van Der Bent C, Papapoulos SE et al. Bone morphogenetic proteins stimulate angiogenesis through osteoblast-derived vascular endothelial growth factor A. Endocrinology 2002; 143: 15451553

23. Kaigler D, Krebsbach PH, Polverini PJ, Mooney DJ. Role of vascular endothelial growth factor in bone marrow stromal cell modulation of endothelial cells. Tissue Eng 2003; 9: 95-103. 